\title{
The Impact of African and Brazilian Zika virus isolates on neuroprogenitors
}

Loraine Campanati $^{1, \#, *}$, Luiza M. Higa ${ }^{2, \#}$, Rodrigo Delvecchio ${ }^{2}$, Paula Pezzuto ${ }^{2}$, Ana Luiza Valadão ${ }^{2}$, Fábio L. Monteiro ${ }^{2}$, Grasiella M.Ventura ${ }^{3}$, Carla Veríssimo ${ }^{1}$, Ana M. Bispo De Filippis ${ }^{4}$, Renato S. Aguiar ${ }^{2}$, Amilcar Tanuri ${ }^{2, *}$.

\section{Affiliations:}

${ }^{1}$ Laboratório de Morfogênese Celular, Instituto de Ciências Biomédicas, Universidade Federal do Rio de Janeiro.

${ }^{2}$ Laboratório de Virologia Molecular, Departamento de Genética, Instituto de Biologia, Universidade Federal do Rio de Janeiro.

${ }^{3}$ Unidade de Microscopia Confocal, Instituto de Ciências Biomédicas, Universidade Federal do Rio de Janeiro.

${ }^{4}$ Laboratório de Flavivírus, Instituto Oswaldo Cruz, Fundação Oswaldo Cruz, Rio de Janeiro, Brazil

${ }^{\#}$ These authors contributed equally to this work.

*Correspondence to: Amilcar Tanuri and/or Loraine Campanati.

\begin{abstract}
In the last few months, an overwhelming number of people have been exposed to the Zika virus (ZIKV) in South and Central America. Here we showed, in vitro, that a Brazilian isolate impacts more severely murine neuronal progenitors and neurons than the
\end{abstract}


African strain MR766. We found that the Brazilian isolate more pronouncedly inhibits neurite extension from neurospheres, alters their differentiation potential and causes neurons to have less and shorter processes. Comparing both lineages using a panel of inflammatory cytokines, we showed, with human neuroblastoma cells, that ZIKV induces the production of several inflammatory and chemotactic cytokines and once again, the Brazilian isolate had a more significant impact. Although much more needs to be studied regarding the association of ZIKV infection and brain damage during development, our study sheds some light into the differences between African and American lineages and the mechanisms by which the virus may be affecting neurogenesis.

Main Text: In the last few months, healthcare professionals in Brazil noticed an alarming surge of fetuses diagnosed with microcephaly and several other brain malformations from mothers who showed typical signs of Zika virus infection during pregnancy (1). At the same time, retrospective statistical analysis from an outbreak (2013-2015) in the French Polynesia showed a correlation between Zika infection and microcephaly and also an increase in the number of patients with Guillain-Barré syndrome $(2,3)$.

Genetic and environmental agents have been linked to neurodevelopmental disorders, when they converge to defects on the mechanisms of proliferation, migration and differentiation of neural stem cells (NSCs) $(4,5)$. Congenital Cytomegalovirus infection is known to cause microcephaly by the inhibition of NSCs differentiation into neurons ( 6 ) and flaviviruses, like the Japanese encephalitis virus (JEV) infect neurons, glial cells and neural stem cells, leading to changes in their differentiation potential (710). Evidence is mounting on the correlation of ZIKV infection to damage to the nervous 
system, but there is a lack of information about the differences between African and Brazilian isolates on neural cells $(11,12)$. ZIKV particles were recently identified in the brain tissue of fetuses diagnosed with microcephaly and other brain damages, whose mothers were infected in the Americas $(12,13)$ and the MR766 African strain was shown to infect human neural stem cells derived from reprogrammed skin cells and to impair the growth of brain organoids (14) (P Garcez et al http://peerj.com/preprints/1817).

Sequencing and phylogenetic data from our group showed that isolates from Brazilian patients are $97-100 \%$ identical to the virus isolated from the outbreak in the French Polynesia, while showing 87-90\% identity to African isolates (11). To date, there is no report of either cases of congenital abnormalities or Guillain-Barré syndrome in Africa, pointing to the possibility that differences in genome sequences of these strains may be associated to different clinical outcomes. In this work, we sought to comparatively investigate the outcomes of the infections of African and Brazilian ZIKV isolates in different cell types.

When the polyprotein sequence from prototypic African isolate MR766 was compared to the pandemic strain circulating in South America, we found an overall identity of $96.4 \%$ and a $98.4 \%$ of similarity. Comparisons of the structural and nonstructural proteins of the Brazilian isolate ZIKV Br 3189 (11) and MR766 showed 129 amino acids changes. Most of these substitutions are conservative and mainly located in the envelope and NS4b proteins, two critical points of the viral proteins. The first main modification acquired by ZIKV Br, is a new, canonical N-Linked glycosylation site located at position 153 of the envelope protein like recently described by cryoelectronmicroscopy (15). Another noticeable cluster of mutation is located at the 
cytoplasmic loop of the NS4b protein. This site is implicated in the induction of membrane synthesis and replication competence in Dengue virus (16), as well as in signal transduction related to malignant transformation in HCV (17) (Figs. S1-S2). These two main differences are found in all ZIKV isolates sequenced in the Americas and deposited in the Genbank site. These unique properties of the Asian lineage showed here could impact the field of vaccine and antiviral development to this new pathogenic agent.

Using both Brazilian and African isolates, we infected neurospheres derived from murine cortex, SH-SY5Y cells (human neuroblastoma cell line), mouse cortical neural stem cells and neurons.

We performed qPCR targeting ZIKV genome (supp. methods) and verified the intracellular presence of total viral RNA and negative-sense RNA strand, the template for viral genome replication, revealing that all cell types were permissive and productively infected by both viruses (Supp. table 1). MR766 infection of human NSCs was described recently (14) and here we showed that ZIKV Br replication in rodent NSCs was more effective than ZIKV MR766. In contrast, MR766 produced higher levels of intracellular RNA than ZIKV Br in neurospheres enriched in neuronal progenitors and SH-SY5Y cells, whose culture is known to have neuroblast-like cells (18).

Neurospheres were infected to up to $72 \mathrm{~h}$ (Fig.1) and we found that infection with both isolates decreased their area (Fig 1G): ZIKV Br by 21\% $\left(3099 \pm 211 \mu \mathrm{m}^{2}\right)$, while MR766 had a less pronounced effect: 9\% $\left(3548 \pm 203 \mu \mathrm{m}^{2}\right)$. By phase contrast and confocal microscopy, mock-infected neurospheres $\left(3907 \pm 239 \mu \mathrm{m}^{2}\right)$ showed exuberant thin cell processes (Fig. 1A) with positive staining for microtubule-associated protein 2 (Map2), a marker of neuronal differentiation (Fig. 1B). MR766 infected neurospheres 
also exhibited Map2 ${ }^{+}$neurites, (Figs. 1C, 1D) although we noticed that in small neurospheres projections were often misshapen and convoluted (Fig. S5). ZIKV Br infection greatly reduced the amount of $\mathrm{Map}^{+}$cellular processes and we noticed Map2cells with progenitor-like morphology migrating out of the spheres (Fig. 1E, 1F and Fig S4).

Differentiated cortical neurons were also infected (Fig.2). Mock infected neurons (Fig.2A) showed long, intricate neurites growing out of the cell body, while MR766 and ZIKV Br infected cells show less and simpler processes (Figs. 2B, 2C). No infection was observed in differentiated neuronal cells with both MR766 and ZIKV Br evidenced by IF using an anti-Flavivirus (4G2) antibody (Supp. methods), but rather the labeling of cells with shorter Map $2^{+}$processes (Figs. 2B, green). In neurospheres, using a higher viral load of MR766, we observed Map2 ${ }^{\text {low }}$ cells stained with 4G2 (Figs. 2D-E), mainly in the periphery of the spheres. Only rarely, we observed double-labeled (Map2/4G2) processes leaving the neurospheres (Fig. S3A and B), which is in accordance with data published recently showing that the ZIKV infection rate in human neurons is low (14).

Taken together, these results show that both viruses are neurotropic, but have different replicative patterns depending on the differentiation status of the host cell, ZIKV Br being more replicative in undifferentiated cells than ZIKV MR766. Interestingly, even with lower levels of ZIKV Br replication in neurospheres, we observed more pronounced effects in neurite outgrowth by this isolate than when compared to ZIKV MR766. This result suggests a stronger impact in neuronal differentiation induced by the Brazilian isolate, which can be of great importance when 
one takes into account the outcome of infections in earlier phases of the nervous system development.

Other flaviviruses infections are associated to elevated levels of proinflammatory cytokines and chemokines that contribute to brain damage $(7,19-21)$. To compare the immune activation caused by both viruses, we investigated the cytokine profile in the supernatant of SH-SY5Y cells infected with MR766 or ZIKV Br and found a significant increase of several cytokines when compared to mock infected cells (Supplementary Table 2). Two pro-inflammatory cytokines IL-1 $\beta$ and TNF $\alpha$, four chemokines IL-8, IP10, RANTES, Eotaxin and growth factors FGF2 and G-CSF were detected in higher concentration in the supernatant of ZIKV Br infected cells, when compared to cells infected with MR766. Unlike expected, most of the cytokines were not modulated by MR766 infection, except the pro-inflammatory IL-6 that was tightly down regulated (Fig.3).

IL-1 $\beta$ and TNF $\alpha$ act as potent mediators of neuronal death in several neurological disorders, West Nile virus and JEV infections (9). In neuroprogenitor cells it has been shown that IL-1 $\beta$ decreases cell proliferation while TNF $\alpha$ induces cell death via caspase8-mediated apoptosis (22). Moreover, high levels of IL-8 have been shown to induce proapoptotic proteins and cell death in cultured neurons (23). RANTES levels are associated with viral encephalites and can be induced by NF-kB activation via IL- $1 \beta$ and TNF $\alpha$ stimulus in glial cells $(20,24)$. IP-10 is a chemokine induced by viral infection in astrocytes that can regulate IFN $\gamma$ levels (25). In our experiment, IFN $\gamma$ had a slight increase despite of IP-10 levels. Eotaxin high levels are also associated to neurodegenerative disorder (26). The growth factors FGF2 and G-CSF are important 
cytokines involved in NSC proliferation and neurogenesis providing neuroprotection and decreasing apoptosis $(27,28)$. These results show that, when the infection by African and Brazilian isolates are compared, ZIKV Br is capable of elicit a stronger immune response, which can also be of significant importance in the pathogenesis of the infection. Cytokine profile analysis can help us understand how immune response stimulated by ZIKV infection could disturb neuroprogenitor cells and contribute to the higher numbers of microcephaly and encephalitis cases described in South America and Asian countries with ZIKV outbreaks (29).

Overall, it is becoming increasingly clear that Zika virus is neurotropic as other flaviviruses. It is not known, however, whether the Brazilian isolate infectivity is different from the African strain and to which extent immune responses are involved in the pathogenesis. Work with animal models will certainly help to clarify theses questions. The work presented here indicates that the ZIKV circulating in South America, belonging to Asian lineage, gained a novel capacity of altering neuroprogenitor cells when compared to the isolate from the Zika forest in Uganda in 1947.

\section{References}

1. A. S. Oliveira Melo et al., Zika virus intrauterine infection causes fetal brain abnormality and microcephaly: tip of the iceberg? Ultrasound in obstetrics \& gynecology : the official journal of the International Society of Ultrasound in Obstetrics and Gynecology 47, 6-7 (2016).

2. V. M. Cao-Lormeau et al., Guillain-Barre Syndrome outbreak associated with Zika virus infection in French Polynesia: a case-control study. Lancet (London, England), (2016).

3. S. Cauchemez et al., Association between Zika virus and microcephaly in French Polynesia, 201315: a retrospective study. Lancet (London, England), (2016).

4. C. Ernst, Proliferation and Differentiation Deficits are a Major Convergence Point for Neurodevelopmental Disorders. Trends Neurosci, (2016).

5. D. Alcantara, M. O'Driscoll, Congenital microcephaly. American journal of medical genetics. Part C, Seminars in medical genetics 166c, 124-139 (2014).

6. X. J. Li et al., Human Cytomegalovirus Infection Dysregulates the Localization and Stability of NICD1 and Jag1 in Neural Progenitor Cells. Journal of virology 89, 6792-6804 (2015).

7. I. M. Ariff, M. C. Thounaojam, S. Das, A. Basu, Japanese encephalitis virus infection alters both neuronal and astrocytic differentiation of neural stem/progenitor cells. Journal of neuroimmune 
pharmacology : the official journal of the Society on NeuroImmune Pharmacology 8, 664-676 (2013).

8. S. Das, A. Basu, Japanese encephalitis virus infects neural progenitor cells and decreases their proliferation. Journal of neurochemistry 106, 1624-1636 (2008).

9. M. Kumar, S. Verma, V. R. Nerurkar, Pro-inflammatory cytokines derived from West Nile virus (WNV)-infected SK-N-SH cells mediate neuroinflammatory markers and neuronal death. Journal of neuroinflammation 7, 73 (2010).

10. J. W. Neal, Flaviviruses are neurotropic, but how do they invade the CNS? The Journal of infection 69, 203-215 (2014).

11. G. Calvet et al., Detection and sequencing of Zika virus from amniotic fluid of fetuses with microcephaly in Brazil: a case study. The Lancet. Infectious diseases, (2016).

12. J. Mlakar et al., Zika Virus Associated with Microcephaly. The New England journal of medicine, (2016).

13. R. W. Driggers et al., Zika Virus Infection with Prolonged Maternal Viremia and Fetal Brain Abnormalities. The New England journal of medicine, (2016).

14. H. Tang et al., Zika Virus Infects Human Cortical Neural Progenitors and Attenuates Their Growth. Cell stem cell, (2016).

15. D. Sirohi et al., The 3.8 A resolution cryo-EM structure of Zika virus. Science (New York, N.Y.), (2016).

16. L. Chatel-Chaix et al., A Combined Genetic-Proteomic Approach Identifies Residues within Dengue Virus NS4B Critical for Interaction with NS3 and Viral Replication. Journal of virology 89, 7170-7186 (2015).

17. E. H. Sklan, J. S. Glenn, in Hepatitis C Viruses: Genomes and Molecular Biology, S. L. Tan, Ed. (Horizon Bioscience Horizon Bioscience., Norfolk (UK), 2006).

18. J. Kovalevich, D. Langford, Considerations for the use of SH-SY5Y neuroblastoma cells in neurobiology. Methods in molecular biology (Clifton, N.J.) 1078, 9-21 (2013).

19. C. Y. Chang et al., Disruption of in vitro endothelial barrier integrity by Japanese encephalitis virus-Infected astrocytes. Glia, (2015).

20. C. J. Chen et al., TNF-alpha and IL-1beta mediate Japanese encephalitis virus-induced RANTES gene expression in astrocytes. Neurochemistry international 58, 234-242 (2011).

21. S. Das et al., Abrogated inflammatory response promotes neurogenesis in a murine model of Japanese encephalitis. PloS one 6, e17225 (2011).

22. J. Guadagno, X. Xu, M. Karajgikar, A. Brown, S. P. Cregan, Microglia-derived TNFalpha induces apoptosis in neural precursor cells via transcriptional activation of the Bcl-2 family member Puma. Cell death \& disease 4, e538 (2013).

23. L. Thirumangalakudi, L. Yin, H. V. Rao, P. Grammas, IL-8 induces expression of matrix metalloproteinases, cell cycle and pro-apoptotic proteins, and cell death in cultured neurons. Journal of Alzheimer's disease : JAD 11, 305-311 (2007).

24. C. Y. Lai et al., Endothelial Japanese encephalitis virus infection enhances migration and adhesion of leukocytes to brain microvascular endothelia via MEK-dependent expression of ICAM1 and the CINC and RANTES chemokines. Journal of neurochemistry 123, 250-261 (2012).

25. S. Bhowmick et al., Induction of IP-10 (CXCL10) in astrocytes following Japanese encephalitis. Neuroscience letters 414, 45-50 (2007).

26. E. Wild et al., Abnormal peripheral chemokine profile in Huntington's disease. PLoS currents $\mathbf{3}$, Rrn1231 (2011).

27. A. Adepoju, N. Micali, K. Ogawa, D. J. Hoeppner, R. D. McKay, FGF2 and insulin signaling converge to regulate cyclin D expression in multipotent neural stem cells. Stem cells (Dayton, Ohio) 32, 770-778 (2014).

28. R. Kadota et al., Granulocyte colony-stimulating factor (G-CSF) protects oligodendrocyte and promotes hindlimb functional recovery after spinal cord injury in rats. PloS one 7, e50391 (2012).

29. G. Carteaux et al., Zika Virus Associated with Meningoencephalitis. The New England journal of medicine, (2016). 
Acknowledgments: the author would like to thank Conselho Nacional de

Desenvolvimento e Pesquisa (CNPq), Fundação de Amparo a Pesquisa do Estado do Rio de Janeiro (FAPERJ) e Departamento de DST, AIDS e Hepatites Virais do Ministério da Saúde do Brasil for funding research in our laboratories. 
Fig. 1: Infection with ZIKV Br inhibits Map2 process elongation and decreases the area of neurospheres. Mock infected neurospheres extend long, Map $2^{+}$processes (A,B), while MR766 infected suffered little with viral infection (C,D). Spheres infected with ZIKV Br (E,F) showed more drastic effect and only few neurites were seen. Mean area of the neurospheres in $\mu \mathrm{m}^{2}(\mathrm{~g}) \pm$ s.e.m. ${ }^{* * *} \mathrm{p}<0,001 ;{ }^{*} \mathrm{p}<0,05$; Student's $t$ test.

Fig. 2: ZIKV infection decreases neuronal branching in culture. Neurons infected with both ZIKV isolates showed less branching (B, MR766; C, ZIKV Br) than Mock infected cells. ZIKV specific antigen labeling was detected specially in cells with few Map2 $2^{+}$processes (B, green). At higher viral loads of MR766 (D-F), we noticed Map2 ${ }^{\text {low }}$ and Map2 ${ }^{-}$cells (arrows) expressing viral antigens (green).

Fig.3: ZIKV Br infection elicits higher levels of cytokine production when compared to ZIKV 766 infection. A detailed table of all cytokines tested can be found in the supplementary methods. 
Fig. 1:
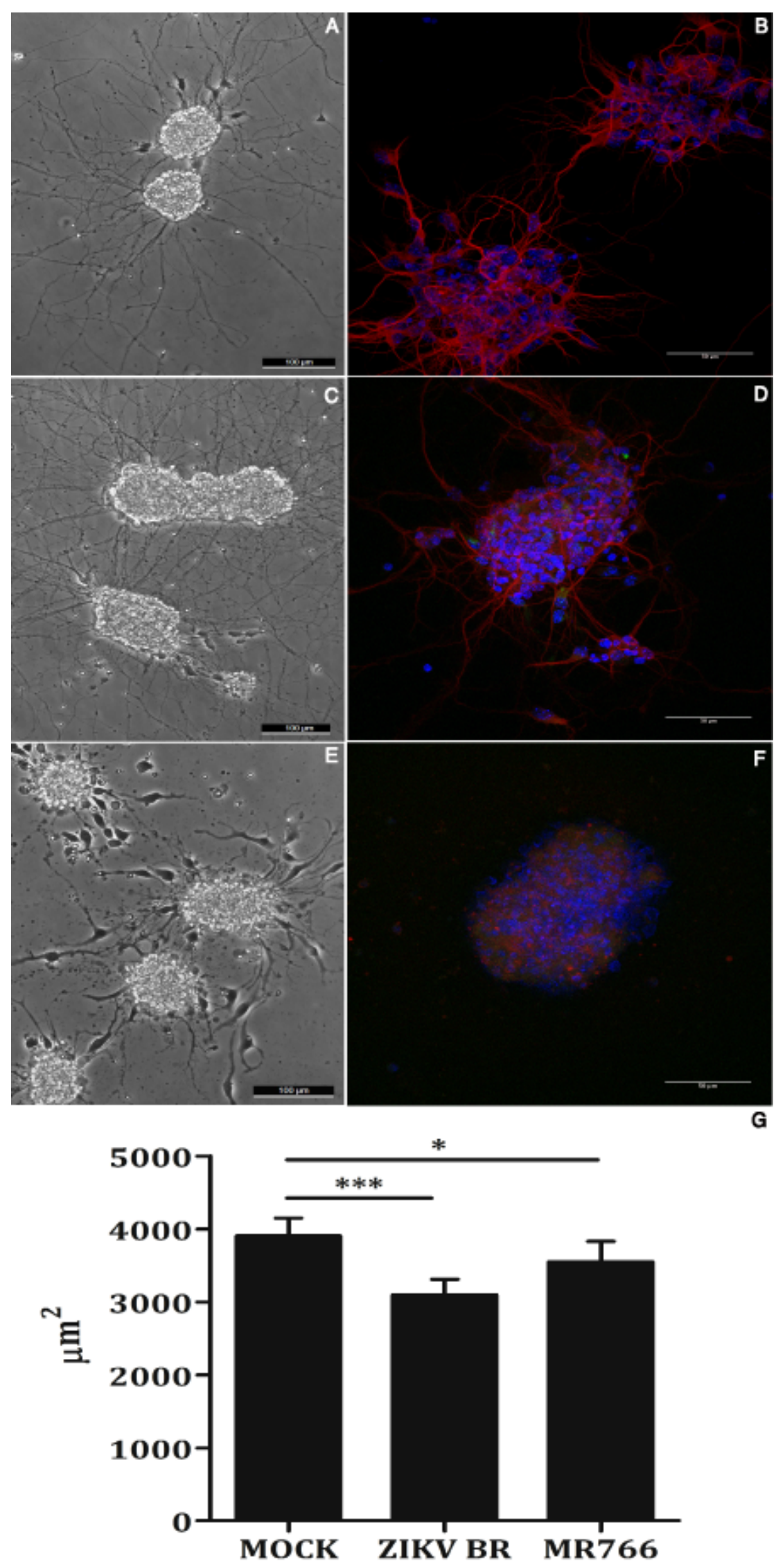
bioRxiv preprint doi: https://doi.org/10.1101/046599; this version posted April 20, 2016. The copyright holder for this preprint (which was not certified by peer review) is the author/funder. All rights reserved. No reuse allowed without permission.

Fig.2:

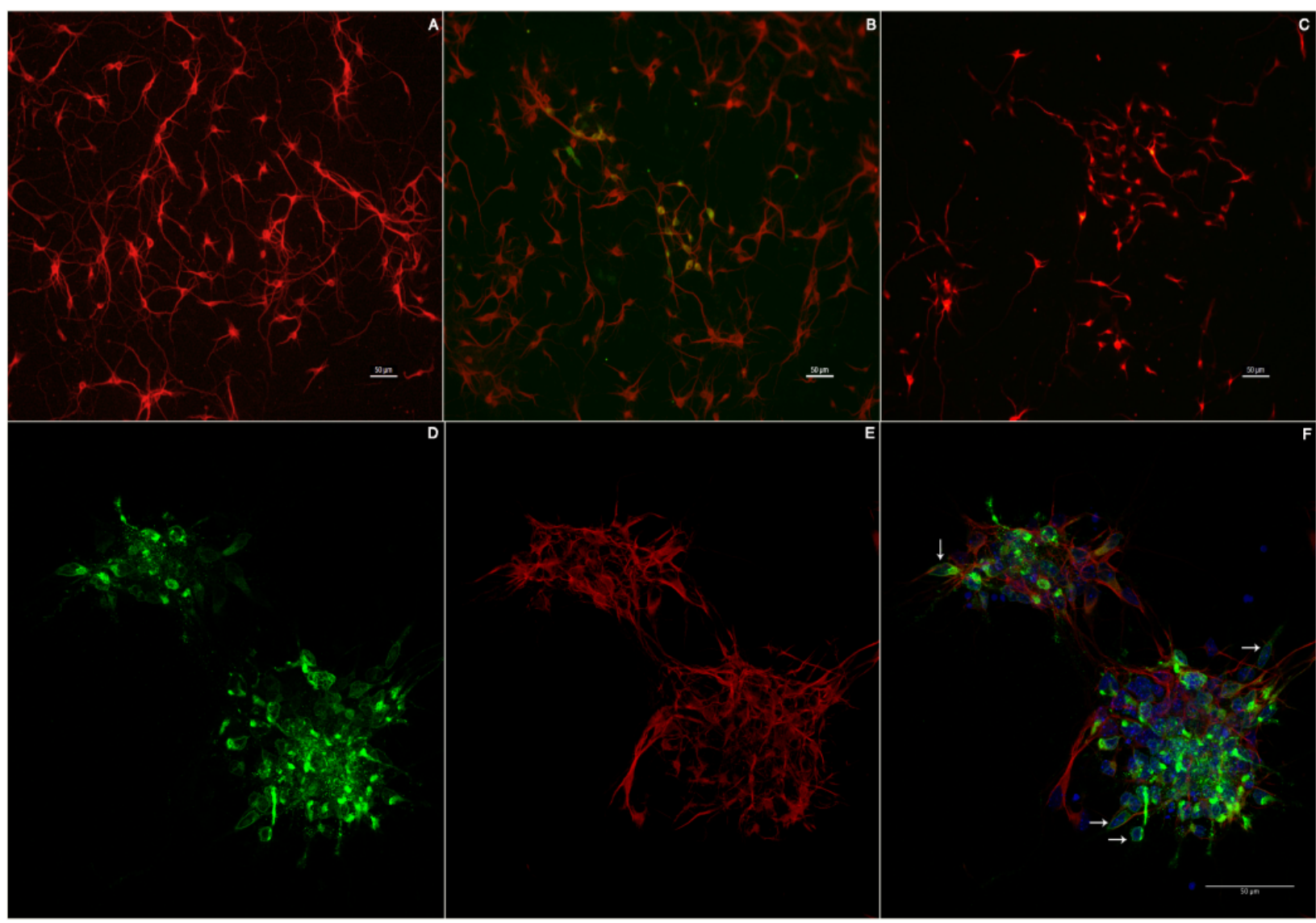


Fig.3:

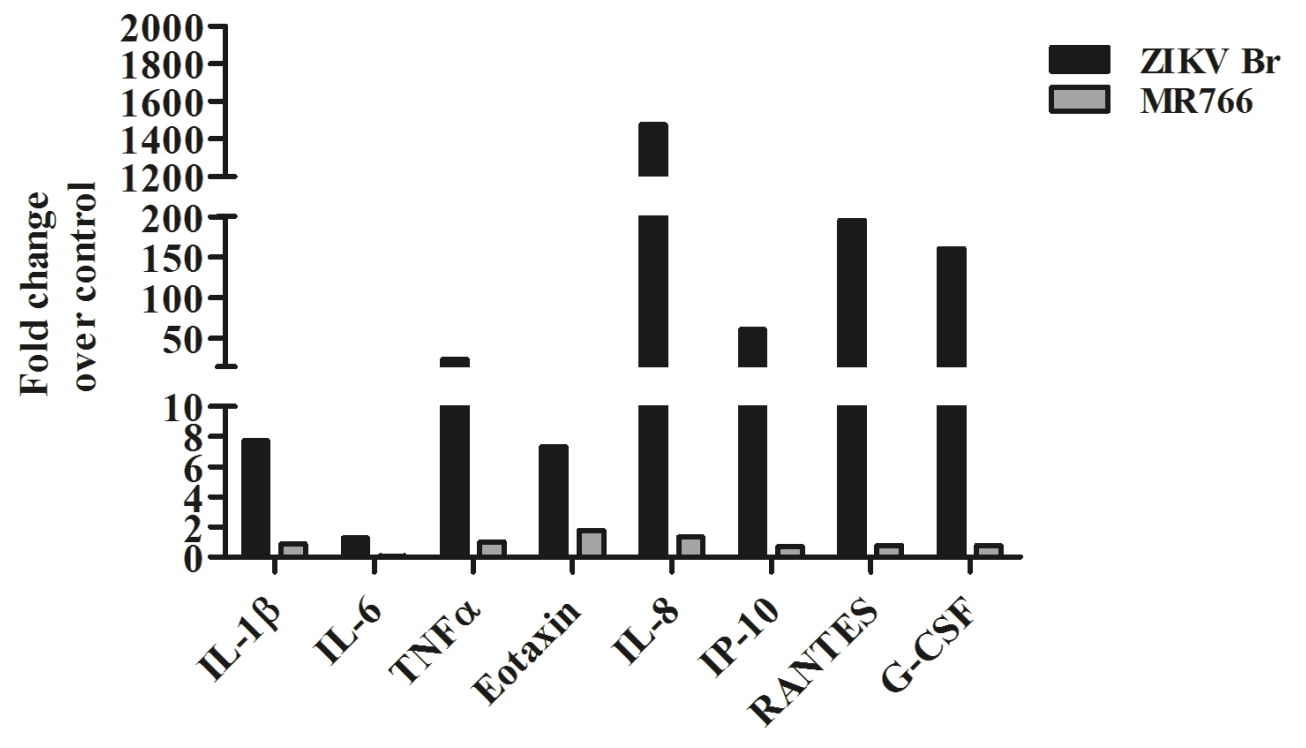




\section{Figure S1}

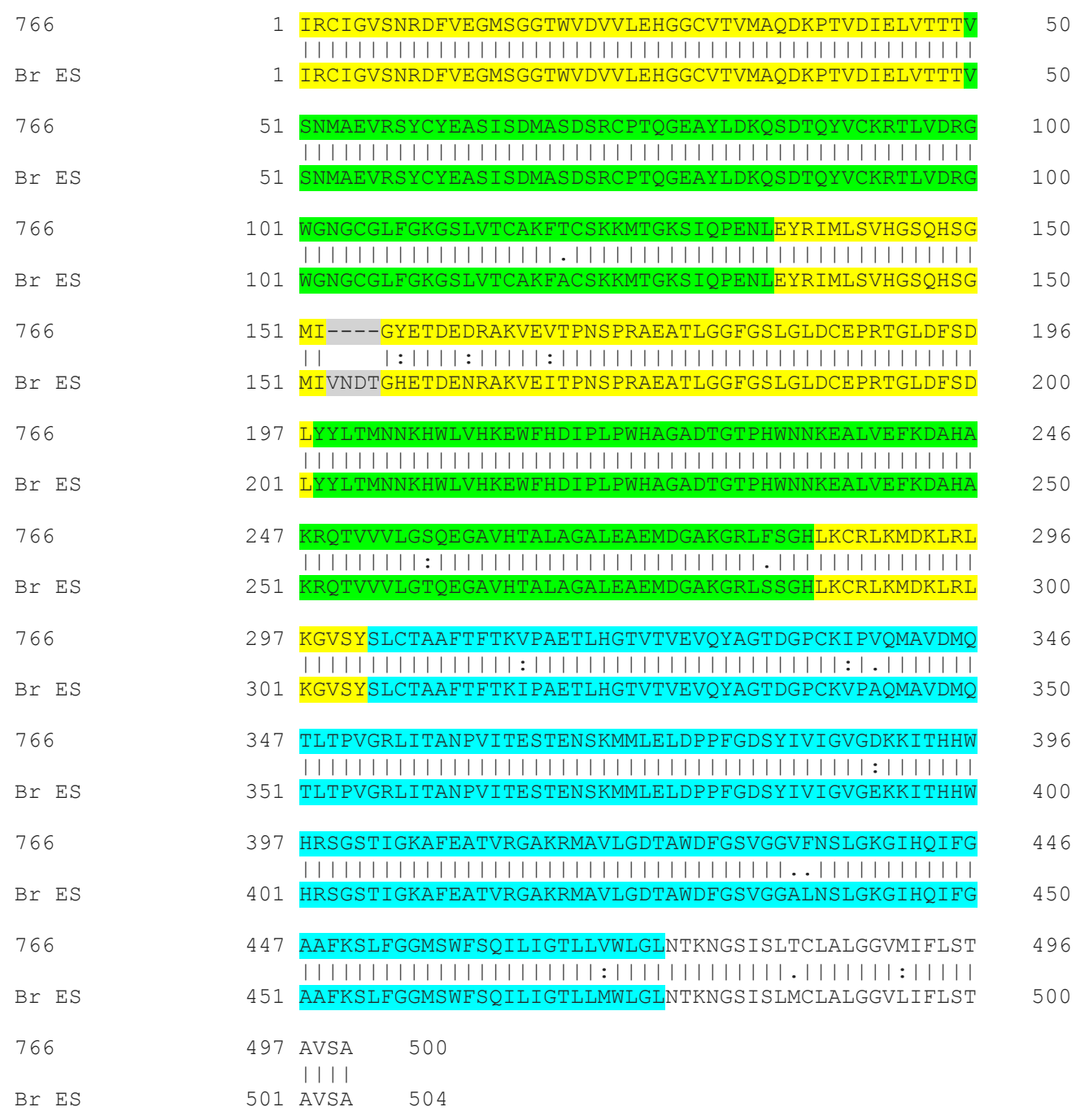

Figure S1 - Amino acid alignment of ZIKV envelope sequence from African 766 (766) prototypic sequence with Brazilian (Br ES) counterpart done with Needle package contained in Clustal W package http://www.ebi.ac.uk/Tools/psa/emboss_needle/). Marked in yellow, green and blue are protein Domains I, II, and III, respectively. The insertion of four amino acid in BR ES Domain I is marked in gray. A vertical line between sequences represents identity and two and one points represents conservative and non-conservative substitutions, respectively. Total identity was $96.2 \%$ and similarity score was $98 \%$. 


\section{Figure S2}

\begin{tabular}{|c|c|c|c|}
\hline ZIKV & 766 & 1 & 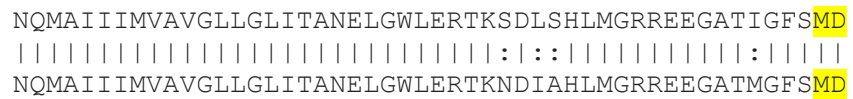 \\
\hline ZIKV & 766 & 51 & IDLRPASAWA IYAALTTFITPAVQHAVTTSYNNYSLMAMATQAGVLFGMG \\
\hline ZIKV & BR & 51 & IDLRPASAWA IYAALTTLITPAVQHAVTTSYNNYSLMAMATQAGVLFGMG \\
\hline ZIKV & 766 & 101 & 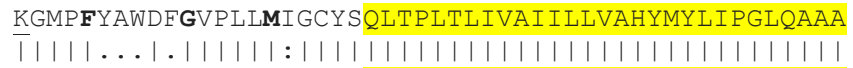 \\
\hline ZIKV & BR & 101 & KGMPFMHGDLGVPLLMMGCYSQLTPLTLIVAI I LLVAHYMYLI PGLQAAA \\
\hline ZIKV & 766 & 151 & $\begin{array}{l}\text { ARAAQKRTAAGIMKNPVVDGIVVTDIDTMTIDPQVEKKMGQVLLIAVAVS } \\
|||||||||||||||||||||||||||||||||||||||||||||||||||| l \mid l\end{array}$ \\
\hline ZIKV & $\mathrm{BR}$ & 151 & ARAAQKRTAAG IMKNPVVDG IVVTDI DTMT I DPQVEKKMGQVLLIAVAIS \\
\hline ZIKV & 766 & 201 & 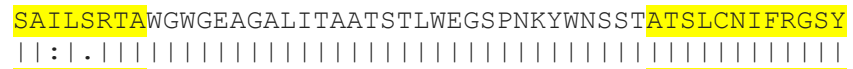 \\
\hline ZIKV & $\mathrm{BR}$ & 201 & SAVLLRTAWGWGEAGALITAATSTLWEGS PNKYWNSSTATSLCNIFRGSY \\
\hline ZIKV & 766 & 251 & $\begin{array}{l}\text { LAGASLIYTVTRNAGLVKRR } \\
||||||||||||||||||||\end{array}$ \\
\hline ZIKV & BR & 251 & LAGASLIYTVTRNAGLVKRR \\
\hline
\end{tabular}

Figure S2- Amino acid alignment of ZIKV NS4B sequence from African MRC 766 prototypic sequence with Brazilian ( $\mathrm{Br} \mathrm{ES}$ ) counterpart done with Needle package contained in Clustal W package http://www.ebi.ac.uk/Tools/psa/emboss_needle/). Marked in yellow are five NS4B transmembrane domains. The underlined sequences represents two DNA binding sequences motifs and in bold are three important amino acids for Dengue virus replication. A vertical line between sequences represents identity and two and one points represents conservative and non-conservative substitutions, respectively. Total identity was $96.2 \%$ and similarity score was $98 \%$. 
bioRxiv preprint doi: https://doi.org/10.1101/046599; this version posted April 20, 2016. The copyright holder for this preprint (which was not certified by peer review) is the author/funder. All rights reserved. No reuse allowed without permission.

\section{Figure S3A}

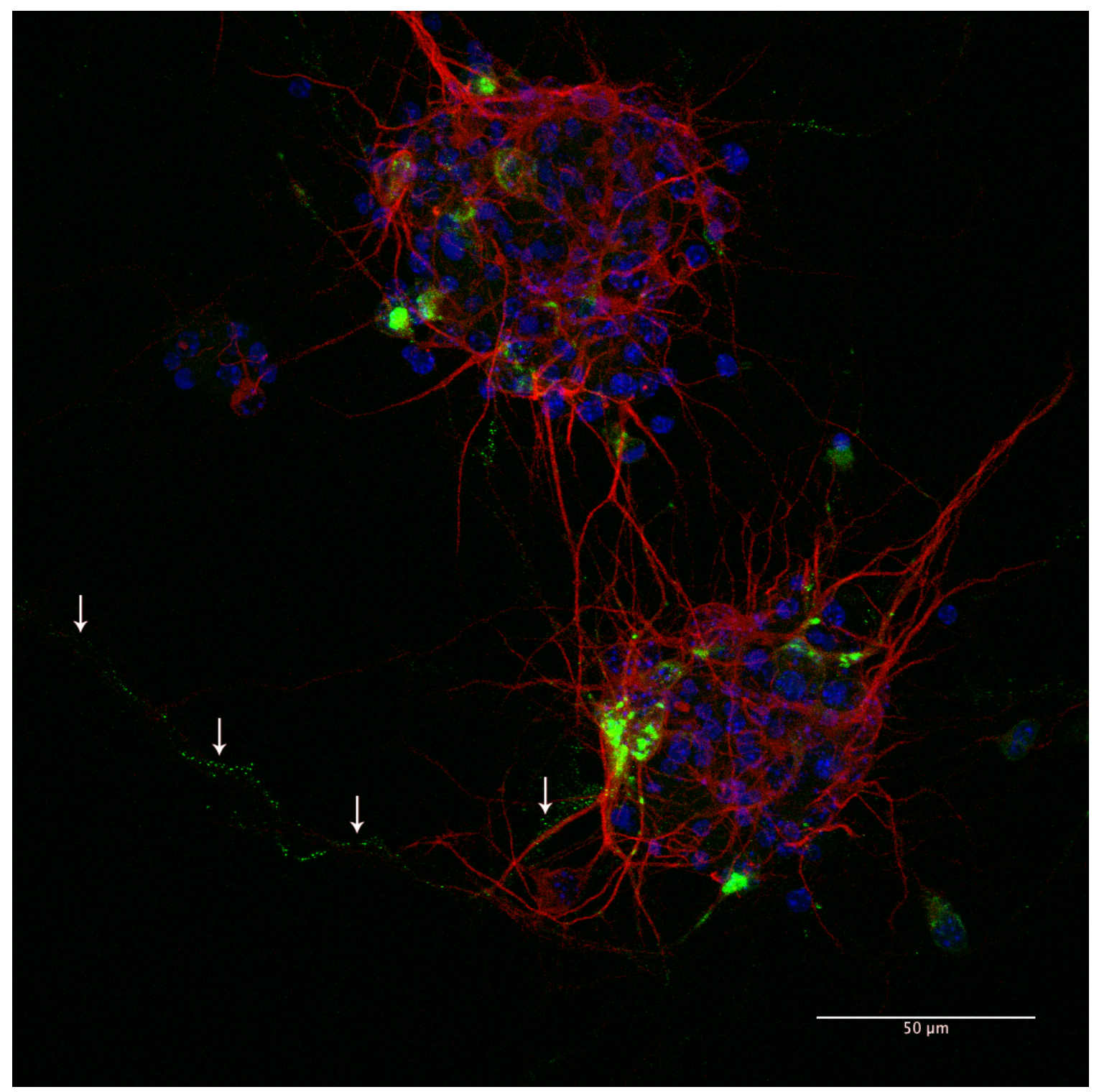




\section{Figure S3B}

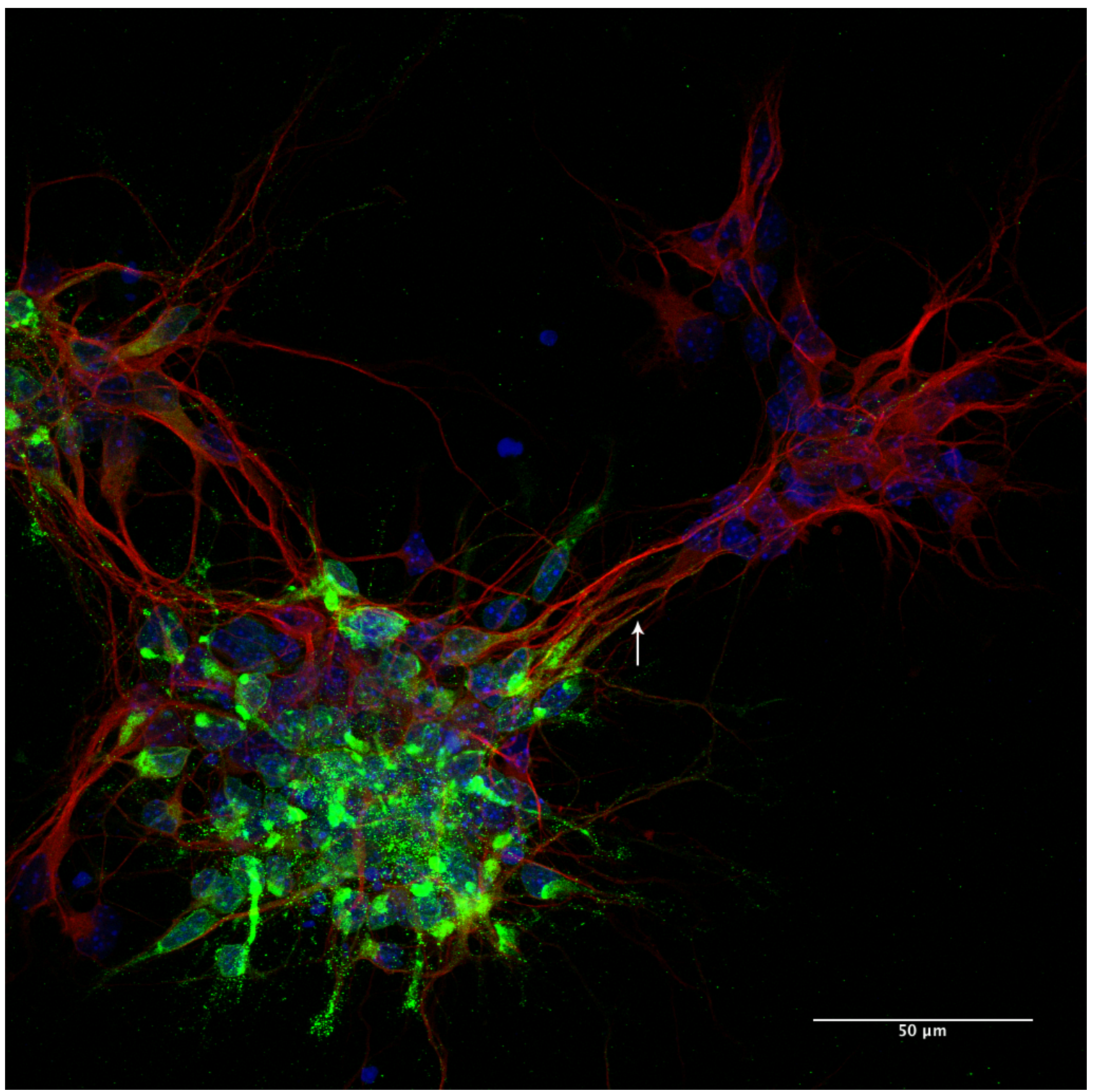

Fig. S3 - Neurospheres infected with $10^{6}$ p.f.u of ZIKV MR766 stained for Map2 (red) and flavivirus specific antigen (green). Only rarely we observed 4G2 positive neurites (arrows) growing out of the spheres. 
bioRxiv preprint doi: https://doi.org/10.1101/046599; this version posted April 20, 2016. The copyright holder for this preprint (which was not certified by peer review) is the author/funder. All rights reserved. No reuse allowed without permission.

\section{Figure S4}

MOCK

MR766
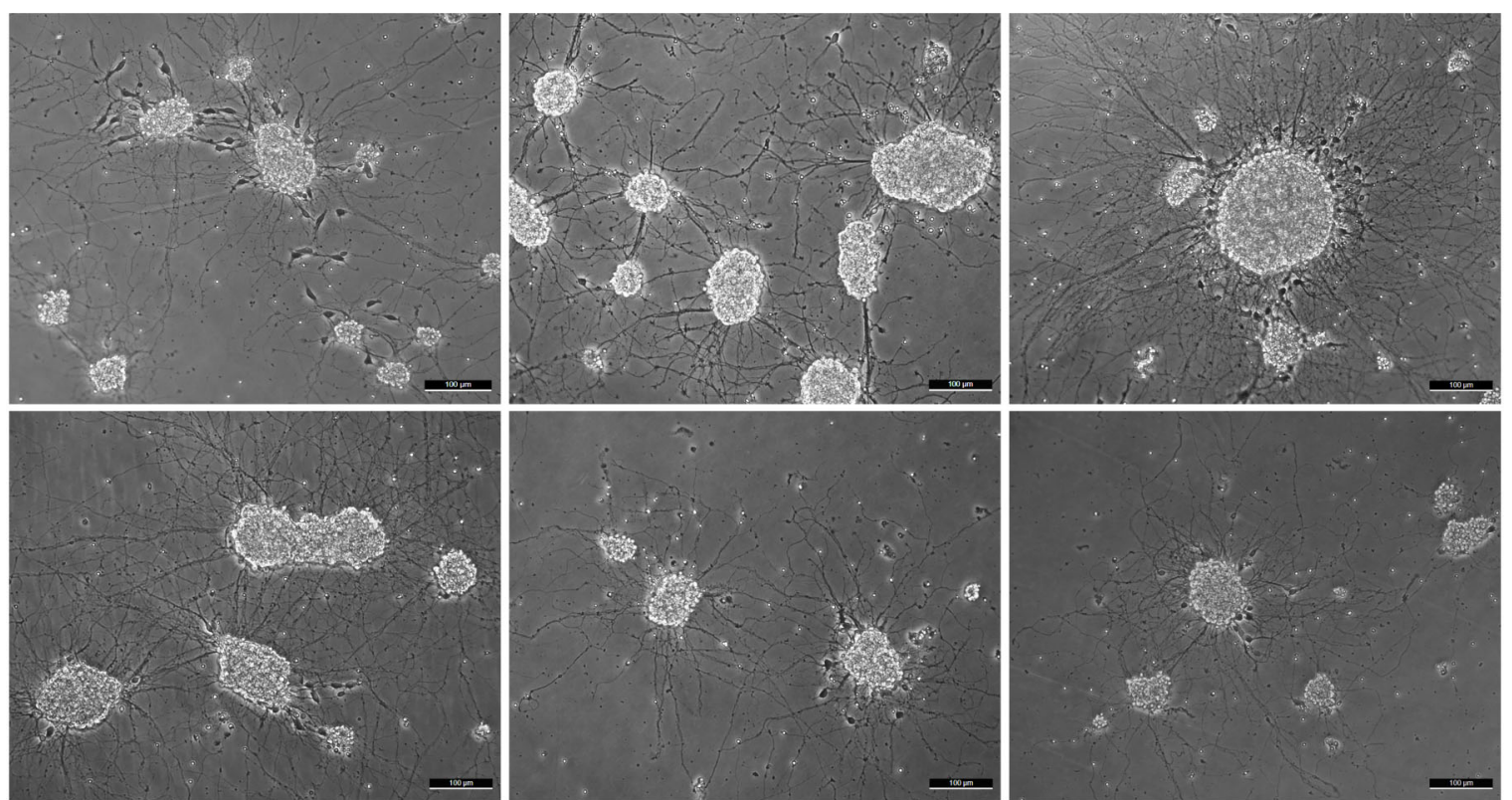

ZIKV Br
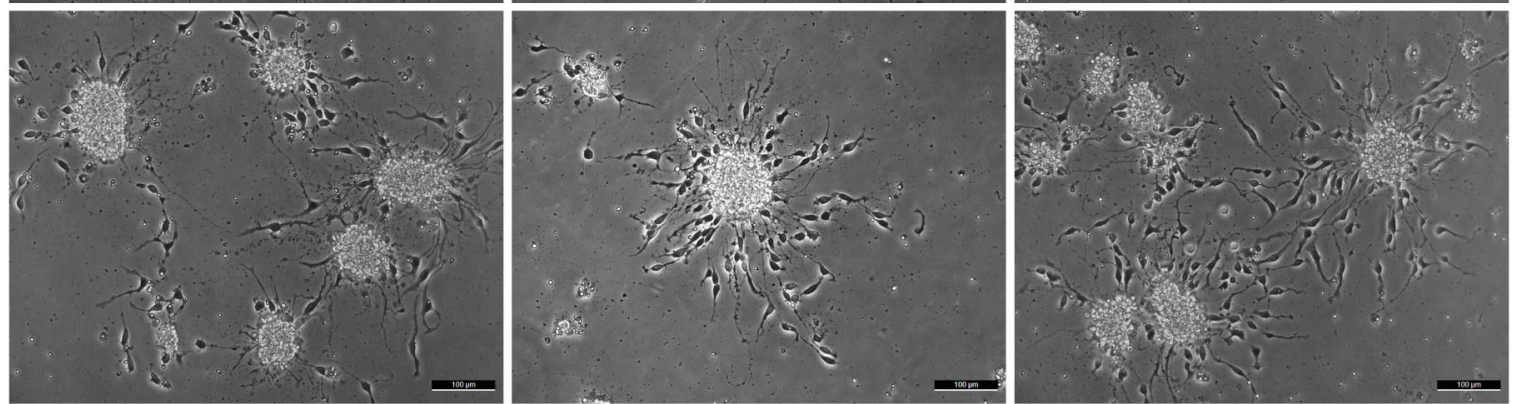

Figure S4 - More examples of infected neurospheres as seen by phase contrast microscopy. 
bioRxiv preprint doi: https://doi.org/10.1101/046599; this version posted April 20, 2016. The copyright holder for this preprint (which was not certified by peer review) is the author/funder. All rights reserved. No reuse allowed without permission.

\section{Figure S5}

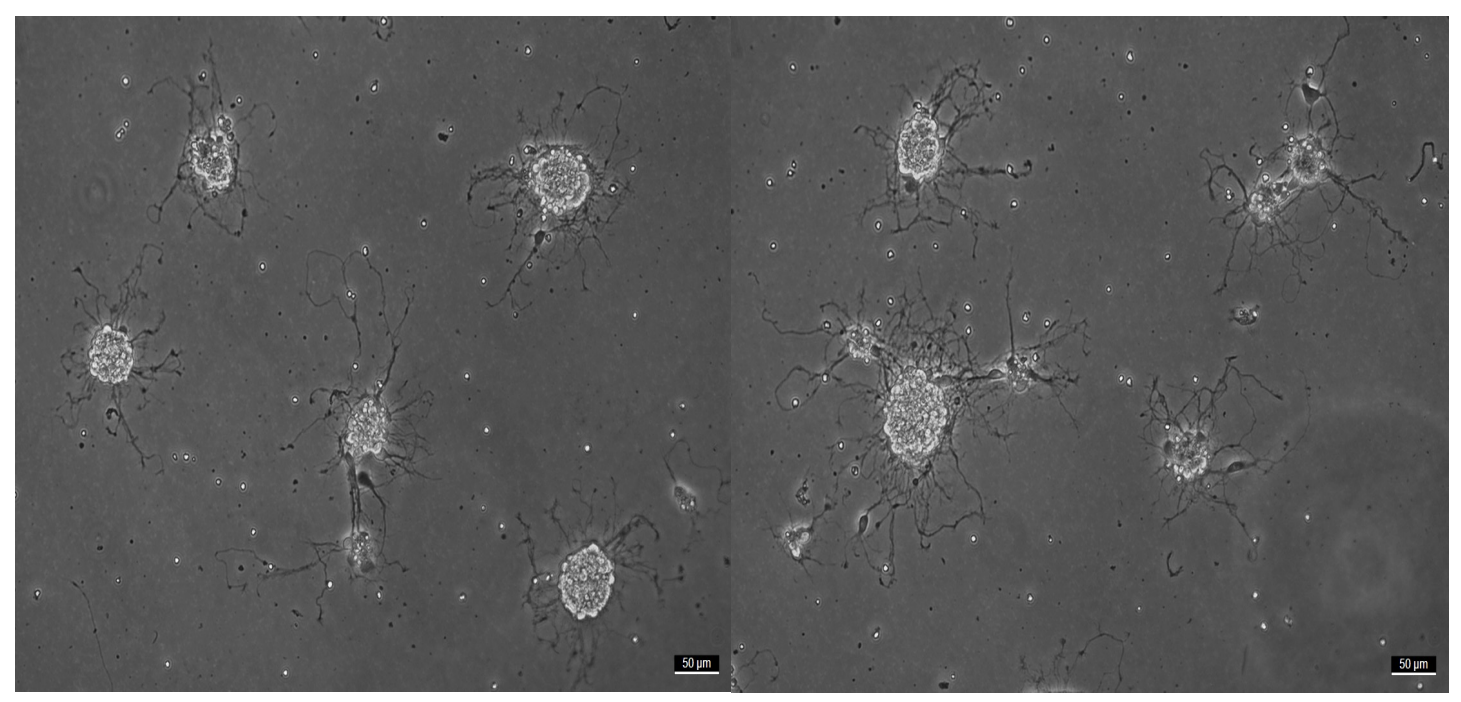

Figure S5 - Smaller neurospheres infected with MR766 had misshapen and convoluted neurite outgrowth. 


\section{Supplementary Table 1}

Quantitative PCR of negative strand and total viral RNA from NSCs, SH-SY5Y and Neurosphere.

\begin{tabular}{|c|c|c|c|c|c|c|}
\hline \multirow{2}{*}{$\begin{array}{c}\text { Experiment } \\
\text { condition }\end{array}$} & \multicolumn{2}{|c|}{ NSCs } & \multicolumn{2}{c|}{ SH-SY5Y } & \multicolumn{2}{c|}{ Neurosphere* } \\
\cline { 2 - 7 } & $\begin{array}{c}\text { RNA negative } \\
\text { strand }\end{array}$ & $\begin{array}{c}\text { Total } \\
\text { RNA }\end{array}$ & $\begin{array}{c}\text { RNA negative } \\
\text { strand }\end{array}$ & $\begin{array}{c}\text { Total } \\
\text { RNA }\end{array}$ & $\begin{array}{c}\text { RNA negative } \\
\text { strand }\end{array}$ & $\begin{array}{c}\text { Total } \\
\text { RNA }\end{array}$ \\
\hline Mock & - & - & - & - & - & - \\
\hline ZIKV MR766 & + & + & +++ & +++ & ++ & ++ \\
\hline ZIKV Br & ++ & ++ & ++ & +++ & + & + \\
\hline
\end{tabular}

$+30<\mathrm{CT}<40 ;++20<\mathrm{CT}<30 ;+++\mathrm{CT}<20$

virus infection with MOI 0.1

*virus infection with 5x104 PFU 


\section{Supplementary Table 1}

Table: Comparison of Inflammatory Cytokines, Chemokines, and Growth Factors levels in the supernatant SH-SY5Y cells (neuroblastoma cell line) after infection with Brazilian and African ZIKV lineages.

\begin{tabular}{|c|c|c|c|c|c|}
\hline \multirow[b]{2}{*}{ Analyte } & \multirow{2}{*}{$\begin{array}{c}\text { Control } \\
\mathrm{pg} / \mathrm{mL}\end{array}$} & \multicolumn{2}{|c|}{$\begin{array}{l}\text { Brazilian ZIKV strain } \\
\text { (MOI 0.1) }\end{array}$} & \multicolumn{2}{|c|}{$\begin{array}{c}\text { African ZIKV strain (MR766) } \\
\text { (MOI 0.1) }\end{array}$} \\
\hline & & $\mathrm{pg} / \mathrm{mL}$ & $\begin{array}{c}\text { Fold } \\
\text { Change }\end{array}$ & $\mathrm{pg} / \mathrm{mL}$ & $\begin{array}{c}\text { Fold } \\
\text { Change }\end{array}$ \\
\hline \multicolumn{6}{|c|}{ Imflammatory Cytokines } \\
\hline IL-1 $\beta$ & 0,37 & 2.86 & 7.73 & 0,32 & 0.86 \\
\hline IL-1ra & 28,13 & 135.23 & 4.81 & 21.68 & 0.77 \\
\hline IL-2 & - & 2,52 & - & - & - \\
\hline IL-4 & 5,09 & 25,48 & 5.01 & 4,82 & 0.95 \\
\hline IL-5 & - & 10.29 & - & - & - \\
\hline IL-6 & 8.75 & 11.24 & 1.28 & 0.63 & 0.07 \\
\hline IL-9 & 1.62 & 9.87 & 6.09 & 1.62 & 1 \\
\hline IL-10 & 39.03 & 47.52 & 1.22 & 37.48 & 0.96 \\
\hline $\mathrm{IL}-12$ & 229.06 & 249.6 & 1.09 & 215.04 & 0.94 \\
\hline IL-13 & 2.98 & 3.74 & 1.26 & 2.84 & 0.95 \\
\hline IL-15 & 7.87 & 15.56 & 1.98 & 7.94 & 1.01 \\
\hline IL1-7a & - & 20.91 & - & 0.77 & - \\
\hline IFNY & 65.15 & 157.16 & 2.41 & 53.9 & 0.83 \\
\hline TNFa & 4.69 & 115.55 & 24.64 & 4.69 & 1.00 \\
\hline \multicolumn{6}{|l|}{ Chemokines } \\
\hline Eotaxin & 13.45 & 98.88 & 7.35 & 24.1 & 1.79 \\
\hline IL-8 & 2.98 & 4398.46 & 1475.99 & 4.01 & 1.35 \\
\hline IP-10 & 259.3 & 15848.65 & 61.12 & 177.77 & 0.69 \\
\hline
\end{tabular}




\begin{tabular}{|l|c|c|c|c|c|}
\hline MCP-1 & 1029.05 & 1429.51 & 1.39 & 1062.24 & 1.03 \\
\hline MIP-1a & 0.39 & 1.66 & 4.26 & 0.26 & 0.67 \\
\hline MIP-1 $\beta$ & - & 2,77 & - & - & - \\
\hline RANTES & 16.03 & 3134.19 & 195.52 & 12.58 & 0.78 \\
\hline Growth Factors & - & 16.89 & - & - & - \\
\hline Basic FGF & 2.01 & 322.88 & 160.64 & 1.57 & 0.78 \\
\hline G-CSF & - & 49.01 & - & - & - \\
\hline GM-CSF & 59,41 & 70,73 & 1.19 & 61,59 & 1.04 \\
\hline IL-7 & - & 36,08 & - & - & - \\
\hline PDGF & 5730.3 & 7383.34 & 1.29 & 4639.69 & 0.81 \\
\hline VEGF & & & & & \\
\hline
\end{tabular}

$\mathrm{IL}=$ interleukin; IFN- $\gamma=$ interferon $\gamma$; TNF- $\alpha=$ tumor necrosis factor $\alpha$; IP $=$ Interferon gamma-induced protein 10; $\mathrm{MCP}=$ Monocyte chemo attractant protein; $\mathrm{MIP}=$ macrophage inflammatory protein; FGF = fibroblast growth factor; G-CSF = Granulocyte colony-stimulating factor; GM-CSF = Granulocyte-macrophage colony-stimulating factor; PDGF = Platelet Derived Growth Factor-BB; VEGF = vascular endothelial growth factor. Fold Change in cytokine level is relative of control. 